УДК 343.9.01343.41

DOI: $10.17223 / 22253513 / 32 / 4$

\title{
И.М. Клейменов
}

\section{СЕКСУАЛЬНОЕ ДОМОГАТЕЛЬСТВО: КРИМИНОЛОГИЧЕСКИЙ И УГОЛОВНО-ПРАВОВОЙ АСПЕКТЫ ${ }^{1}$}

\begin{abstract}
Показано, что сексуальное домогательство на рабочем месте со стороны руководителя или работодателя характеризуется повышенной общественной опасностью. Оно оказывает длительное психотравмирующее воздействие на жертву, зачастую ставит ее в безвыходное положение, посягает на гражданские права и свободы, подрывает авторитет власти. Предлагается дополнить Уголовный кодекс Российской Федерации статьей «Сексуальное домогательство», устанавливающей уголовную ответственность за сексуальное домогательство при приеме на работу или на рабочем месте. Установление такой ответственности отвечает актуальному вызову правовой защиты жертв сексуального домогательства и соответствует общемировой тенденции усиления противодействия дискриминации личности на рабочем месте.

Ключевые слова: сексуальное домогательство, рабочее место, злоупотребление властью, криминализация.
\end{abstract}

Сексуальное домогательство является актуальной глобальной проблемой. Конечно, острота этой проблемы меняется в зависимости от культурного наследия, взаимоотношения полов, уровня женской эмансипации, отношения к женщинам в обществе, состояния их правовой защищенности и других обстоятельств, но нет такого государства, где бы ее не существовало. Однако не во всех странах эту проблему исследуют и разрабатывают меры правового реагирования.

Между тем международное сообщество констатирует высокую актуальность сексуального домогательства, рассматривает его как форму дискриминации и насилия и предлагает принимать законодательные и иные меры защиты потенциальных жертв, прежде всего женщин. Так, ст. 40 Конвенции Совета Европы по предотвращению и борьбе с насилием в отношении женщин и насилием в семье утверждает императив: «Стороны принимают необходимые законодательные или иные меры, гарантирующие, что любая форма нежелательного вербального, невербального или физического поведения сексуального характера, целью или последствиями которого является нанесение ущерба достоинству лица, в частности, путем создания угрожающих, враждебных, унижающих достоинство, оскорби-

\footnotetext{
${ }^{1}$ Статья подготовлена в рамках исследования № 18-IP-02, поддержанного НИУ ВШЭ Санкт-Петербург.
} 
тельных и агрессивных условий, подвергается уголовным или иным юридическим санкциям» [1]. В ст. 16 Модельного закона о государственных гарантиях равных прав и равных возможностей для мужчин и женщин устанавливаются гарантии на запрет сексуального домогательства и преследования лиц разного пола со стороны работодателя: «Работодатель не имеет права подвергать работающих лиц независимо от пола сексуальному домогательству, а также давлению или преследованию в связи с отказом в его (ее) сексуальных домогательствах и в случае жалобы на работодателя в связи с половой дискриминацией на рабочем месте. В случае сексуального домогательства, оказания давления или преследования работника по вышеуказанным мотивам работодатель несет ответственность в соответствии с национальным законодательством» [2. С. 328-341].

Как отмечено в официальных материалах Комитета министров Совета Европы, «согласно примерным подсчетам, исходящим из шести европейских исследований, от 45 до 85\% женщин подвергаются сексуальному домогательству на рабочих местах и от 5 до 22\% - подают жалобу. Исследования, проведенные по данному вопросу, делают упор на сексуальное домогательство на рабочих местах. Проблема домогательства, которому женщины подвергаются в общественных местах, изучается достаточно редко» [3].

По данным проведенного нами в мае 2018 г. анкетирования 342 жителей Санкт-Петербурга на вопрос: «Сталкивались ли Вы или Ваши знакомые с сексуальным домогательством?», - получены следующие ответы: нет $-42,6 \%$; один раз - 12,5\%; несколько раз - 19,5\%; довольно часто $11,6 \%$, затрудняюсь ответить - 14,3\%. Таким образом, около половины респондентов указали на реальность поставленной проблемы.

Ответы респондентов на просьбу измерить (по 100-балльной шкале) актуальность проблемы сексуального домогательства в России распределились следующим образом: до 25 баллов - 9,0\%; 26-50 баллов - 36,5\%; 51-75 баллов - 33,2\%; 76-100 баллов - 21,3\%. Как видим, большая часть оценок характеризует проблему как весьма актуальную.

В июне 2018 г. организации Edison Research и Marketplace опубликовали результаты проведенного ими исследования, посвященного сексуальному домогательству на рабочем месте, в процессе которого были опрошены 1044 американцев в возрасте от 18 лет. Согласно полученным данным, $21 \%$ респондентов отметили, что они были жертвами сексуального домогательства на рабочем месте, 55\% из их числа указали, что это в целом повредило их карьере, многие были вынуждены сменить место работы [4]. Указанное исследование наглядно демонстрирует, насколько значительны последствия сексуального домогательства: сломанная карьера жертвы, перемена места работы, что, конечно, означает материальные и моральные потери.

Вместе с тем здесь нет ответа на вопрос, кто же осуществляет сексуальное домогательство - коллега по работе или начальник. Между тем это принципиальный вопрос, поскольку он помогает выделить разные виды сексуального домогательства на рабочем месте: горизонтальное (между 
равными по служебному статусу лицами) и вертикальное (между руководителем и подчиненным). Их общественная опасность различна: второй вид заметнее опасней первого. Горизонтальное сексуальное домогательство сродни бытовому и отличается от последнего только местом совершения. В свою очередь, бытовое сексуальное домогательство в современных условиях - это не что иное, как предложение вступить в сексуальный контакт. 76,4\% опрошенных нами респондентов согласились с утверждением, что сексуальное домогательство - это откровенный призыв любого мужчины к половому акту, выраженный в словах или жестах, циничных прикосновениях. Если такое предложение сопровождается физическим или психическим насилием или угрозой его применения либо совершается в отношении лица, не достигшего шестнадцатилетнего возраста или несовершеннолетнего, то налицо посягательство на половую неприкосновенность и половую свободу личности либо общественную нравственность, за которое наступает уголовная ответственность, в противном случае - правонарушение отсутствует (если в нем нет признаков иного деяния). Законопроект о дополнении КоАП РФ новой статьей «Сексуальное домогательство» (в которой домогательство характеризуется как нежелательное поведение, приставания сексуального характера, попытка установления интимного контакта, ухаживания, сексуальные притязания в скрытой или явной форме, просьбы о сексуальных услугах, прочие словесные или физические действия сексуального характера, совершенные мужчиной в отношении женщины против ее воли), был отклонен Государственной Думой РФ [5].

Для массового сознания характерно именно такое, по существу, бытовое, понимание сексуального домогательства. 67,7\% опрошенных нами граждан выразили согласие с суждением, что граница между ухаживанием (флиртом) и сексуальным домогательством пролегает там, где существует нежелание девушки или женщины отвечать на знаки внимания. На вопрос: «Где, по Вашему мнению, риск подвергнуться сексуальному домогательству наиболее велик?», - респонденты ответили:

- на улице - 38,7\%;

- в общественном транспорте - $15,6 \%$;

- в учебном заведении - $8,5 \%$;

- в местах проведения досуга - 51,4\%;

- на работе $-27,4 \%{ }^{1}$.

Таким образом, сексуальное домогательство в социальной психологии воспринимается преимущественно как бытовая проблема, которая, кроме всего прочего, имеет виктимологический аспект. По мнению опрошенных граждан, в детерминации сексуального домогательства просматривается и вина жертв, которых респонденты упрекают в откровенных нарядах $(41,0 \%)$, репутации доступной женщины $(32,5 \%)$, легкомысленном поведении $(58,0 \%)$, готовности к рискованному флирту $(22,6 \%)$. Отсюда и солидарность респондентов с рекомендациями, направленными на снижение

\footnotetext{
${ }^{1}$ Сумма ответов больше $100 \%$, поскольку респонденты могли выбрать более одного ответа.
} 
риска сексуального домогательства, которые адресованы потенциальным жертвам: не знакомиться на улице, в общественном транспорте $(25,0 \%)$; быть осторожнее со знакомствами в социальных сетях $(42,5 \%)$; избегать посещения ночных клубов $(38,7 \%)$; не ужинать с малознакомыми людьми (29,7\%). Виктимологический анализ проблемы дает основания для вывода о том, что правовые запреты бытового сексуального домогательства бессмысленны. В условиях падения нравов, продемонстрированного «русскими девушками» на чемпионате мира по футболу 2018 г. [6], грани между запретным и дозволенным стираются до основания.

Иное дело - сексуальное домогательство на рабочем месте в отношениях «руководитель-починенный», «работодатель-работник». Такое домогательство сродни сексуальной эксплуатации, поскольку домогатель склоняет жертву к сексуальным контактам, используя властный ресурс. Жертва ощущает свою несвободу, она вынуждена подчиняться. «Сексуальное домогательство - это история не про секс и романтику, а про власть. Конкретный мужчина показывает женщине, что она для него никто и, если он захочет, она отдаст ему все, что он попросит. Женщина идет на это, потому что живет в контексте, где не может выйти, хлопнуть дверью и уйти из профессии. Никто не должен стоять перед выбором: отдаться принудительно и сделать карьеру или воспользоваться своим талантом и добиться вершин. Этот выбор негуманный. Даже если женщин никто не тащит силком, в таких ситуациях они отлично понимают, как им все обрубят в профессиональной области, если они не согласятся. Это невидимые веревки, но они ничем не лучше настоящих» [7. С. 26].

Такое сексуальное домогательство можно также уподобить коррупции. На первом месте здесь всегда будет извращенная власть, которая дает возможность получать сексуальные услуги либо обогащаться. Власть характеризуется не ее позитивным предназначением - действовать в общественных интересах, а произволом. Еще Платон утверждал, что всякая власть, поскольку она власть, имеет в виду благо никого иного, как тех, кто ей подвластен и ею опекаем - в общественном или частном порядке [8. C. 585].

Сексуальное домогательство со стороны лиц, облеченных властью, вызывало презрение окружающих с древних времен. Достаточно вспомнить историю изгнания последнего царя Древнего Рима Тарквиния Гордого [9. С. 47-53]. Напротив, похвалу вызывало благородное поведение Александра Македонского и Сципиона Африканского по отношению к пленницам [10. С. 351]. Глобальные скандалы последнего времени, связанные с сексуальным домогательством (Вестминстерский сексуальный скандал 2017 г., связанный с недостойным поведением ряда видных британских политиков, история американского кинопродюсера Харви Вайнштейна и др.), судя по комментариям, в основном порицаются аудиторией средств массовой информации.

Очевидно, что общественная опасность сексуального домогательства, совершенного лицами, наделенными властными полномочиями (вертикального), значительно выше, чем бытового (горизонтального) сексуально- 
го домогательства. Фома Аквинский писал: «Любое величие, даже во временных благах, делает грех более тяжким, согласно этим словам (Прем. 6: 8): Начальствуюшим предстоит строгое испытание... из-за особой несовместимости греха с высоким положением лица: например, если князь, который должен быть защитником справедливости, поступает несправедливо, или если священник, который дал обет чистоты, совершает прелюбодеяние... из-за того, что подается дурной пример и приводятся в смущение люди... грехи важных лиц становятся известны многим и потому сильнее склоняют людей к недостойному» [11. С. 100].

Повышенная общественная опасность сексуального домогательства со стороны руководителей и работодателей заключается в том, что жертва посягательства ставится зачастую в безвыходное положение, по существу, приводится в рабское состояние. Речь здесь идет, например, о трудовых мигрантах, нанимающихся на работу в частные домовладения. В зоне риска секретарши, продавщицы, медсестры, стюардессы, проводницы [12]. Потеря работы для них означает утрату источника существования, а зачастую - и жизненной перспективы.

Повышенная общественная опасность сексуального домогательства состоит также в его психотравмирующем воздействии на жертву и ее ближайшее окружение. «Во время собеседования при приеме на работу руководитель фирмы вдруг спросил: “А как вы отнесетесь к тому, что в ваши обязанности будет входить оказание услуг сексуального характера начальнику?" Я опешила. Он задал этот вопрос таким же спокойным, деловым тоном, которым вел и всю остальную беседу... Предложил не отказываться сразу, подумать. Сказал, что это оплачивается отдельно... Сегодня, спустя пятнадцать лет, вспоминая ту историю, я переживаю те же эмоции что и тогда: негодование, отвращение, отчаяние, внутри все клокочет. И при этом я чувствую себя совершенно беспомощной. Тот человек еще до встречи со мной определил для себя роль женщины в обществе - второстепенное существо, которое должно подчиняться, которое не спрашивают, а ставят перед фактом собственного выбора» [13].

Сказанное свидетельствует о необходимости и целесообразности уголовно-правовой защиты жертв сексуального домогательства, в чем дополнительно убеждает анализ зарубежного уголовного законодательства.

Уголовный кодекс Индии (принятый в 1860 г. и действующий до настоящего времени) содержит две статьи соответствующей направленности: ст. 354 «Нападение или криминальное насилие в отношении женщины с целью оскорбить ее достоинство» (с санкцией до двух лет тюремного заключения) и ст. 509 «Слово, жест или поступок, оскорбляющие достоинство женщины» (с санкцией до одного года лишения свободы). В 2013 г., после принятия Закона о сексуальном домогательстве женщин на рабочем месте [14], УК Индии дополнен ст. 354А «Сексуальное домогательство», которое трактуется в контексте Закона достаточно широко, включая требования или просьбы сексуальной близости, сексуально окрашенные замечания, принудительную демонстрацию порнографии. Уголовное наказание за сексуаль- 
ное домогательство дифференцировано в зависимости от его характера и предусматривает тюремное заключение на срок до трех лет или штраф либо лишение свободы со штрафом. Заметим попутно, что УК Индии одновременно был дополнен ст. 354В «Действие с целью раздеть женщину», ст. 354С «Вуайеризм», ст. 354С «Преследование». Характерно, что в последнем случае уголовно наказуемым признается не только физическое преследование, порождающее страх женщины за свою безопасность, но и «электронное преследование» - посредством Интернета или электронной почты [15].

Уголовный кодекс Испании рассматривает сексуальное домогательство в качестве разновидности преследования сексуального характера и включает ст. 184 в следующей редакции: «Тот, кто осуществляет домогательство сексуального характера в свою пользу или пользу третьего лица, используя свое должностное или аналогичного характера положение, подразумевая или открыто говоря о причинениях в случае отказа вреда, связанного с законными намерениями потерпевшего в области указанных отношений, наказывается как исполнитель сексуального преследования арестом на срок от двенадцати до двадцати четырех выходных дней или штрафом в размере от шести до двенадцати месячных заработных плат» [16]. Как видим, данный запрет не содержит гендерного признака (жертвами могут быть и мужчины), в нем нет ограничений о месте преступления (оно может быть совершено не только на рабочем месте).

Алжирский уголовный кодекс в ст. 341-бис определяет сексуальное домогательство как злоупотребление властными полномочиями, установленными служебным или профессиональным положением, которое выражается в приказах, угрозах, накладывании ограничений или оказании давления на человека с целью получения сексуальных услуг. Наказание за это преступление - тюремное заключению от двух месяцев до одного года и штраф в размере от 50 до 100 тыс. алжирских динаров [17].

В России сексуальное домогательство криминализировано частично как понуждение к действиям сексуального характера. Часть 1 ст. 133 Уголовного кодекса Российской Федерации (УК РФ) устанавливает запрет понуждения лица к половому сношению, мужеложству, лесбиянству или совершению иных действий сексуального характера путем шантажа, угрозы уничтожением, повреждением или изъятием имущества либо с использованием материальной или иной зависимости потерпевшего (потерпевшей). Преступление совершается путем психического насилия. Не могут рассматриваться как понуждение к действиям сексуального характера действия лица, добившегося согласия потерпевшего (потерпевшей) на совершение действий сексуального характера путем обмана или злоупотребления доверием (например, заведомо ложного обещания вступить в брак и т.п.) [18]. Деяние наказывается штрафом в размере до 120 тыс. руб. или в размере заработной платы или иного дохода осужденного за период до одного года, либо обязательными работами на срок до 480 часов, либо исправительными работами на срок до двух лет, либо принудительными работами на срок до одного года, либо лишением свободы на тот же срок. 
Часть вторая ст. 133 УК РФ содержит квалифицированный состав понуждения к действиям сексуального характера. То же деяние, совершенное в отношении несовершеннолетнего (несовершеннолетней), наказывается принудительными работами на срок до пяти лет с лишением права занимать определенные должности или заниматься определенной деятельностью на срок до трех лет или без такового либо лишением свободы на срок до пяти лет с лишением права занимать определенные должности или заниматься определенной деятельностью на срок до трех лет или без такового.

Изучение материалов уголовных дел показывает, что по ст. 133 УК РФ, как правило, осуждаются лица, обращающиеся к шантажу как способу понуждения к действиям сексуального характера. Так, А. осужден к наказанию в виде штрафа в размере 30 тыс. руб. за совершение преступления, предусмотренного ч. 1 ст. 133 УК Российской Федерации, которое было совершено при следующих обстоятельствах. А. в ходе беседы с Г. - братом его жены - стало известно, что у последнего на мобильном устройстве имеются фотографии Ш. в обнаженном виде, которые Г. в последующем продемонстрировал А. Воспользовавшись этим, А. сообщил Ш. о том, что у него имеются соответствующие фотографии, и под угрозой их распространения, пытался добиться согласия Ш. на вступление с ним в половую связь ${ }^{1}$.

Как видим, содержание ст. 133 УК РФ и практика ее применения не могут обеспечить адекватного уголовно-правового противодействия сексуальному домогательству, которое связано с обманом, злоупотреблением доверием жертвы, посулами различного рода. За пределами уголовноправового регулирования остаются, например, достаточно распространенные предложения работодателей об оказании услуг сексуального характера при приеме на работу, адресованные лицам, желающим трудоустроиться. Другой пример: руководитель, предлагающий подчиненному продвижение по службе за совершение с ним действий сексуального характера, не будет подлежать уголовной ответственности по ст. 133 УК РФ. Вместе с тем высокая общественная опасность такого поведения является очевидной.

По данным Судебного департамента при Верховном Суде РФ, в 2016 г. за понуждение к действиям сексуального характера, совершенное в отношении взрослых, были осуждены 5 человек (3 - к обязательным работам, 1 - к штрафу, 1 человек освобожден от наказания), в 2017 г. в качестве подсудимых фигурировали 13 человек (2 были осуждены к лишению свободы условно, 1 - к исправительным работам, 3 - к обязательным работам, 3 - к штрафу, 1 - освобожден от наказания, 3 дела были прекращены). По ч. 2 ст. 133 УК РФ в 2016 г. осуждены 23 человека (12 - к реальному лишению свободы, 10 - к лишению свободы условно, 1 - к ограничению свободы, одно дело прекращено), в 2017 г. - 33 человека (16 - к реальному лишению свободы, 15 - к лишению свободы условно, 1 - к принудительным работам, 1 - к штрафу).

\footnotetext{
${ }^{1}$ Приговор мирового судьи судебного участка № 95 Кировского района г. Махачкалы, Республика Дагестан 05.07.2017 г. (дело № 1-10/2017).
} 
Такая судебная практика противодействия насильственному сексуальному домогательству явно неадекватна (в отношении как числа осужденных, так и примененных к ним мер наказания) общественной опасности и распространенности этого негативного явления. Опрошенные нами респонденты оценили подобную практику следующим образом:

a) в этом во многом виноваты сами жертвы, они терпят и молчат $-50,9 \%$;

б) достоинство женщин в стране плохо защищено - 22,0\%;

в) правоохранительные органы плохо работают - 32,1\%;

г) суды недостаточно объективны в принятии решений $-27,4 \%$;

д) иное $-2,8 \%$.

На вопрос: «Какую ответственность должно нести лицо, виновное в сексуальном домогательстве?»,- респонденты ответили:

а) дисциплинарную (увольнение от должности) - 25,0\%;

б) материальную (возмещать моральный ущерб) - 32,1\%;

в) административную (дополнить КоАП РФ новой статьей) - 25,5\%;

г) уголовную (дополнить УК РФ новой статьей) - 61,3\%.

В этой связи актуален вопрос о дополнении УК РФ специальным составом сексуального домогательства. Так, внесено предложение включить в УК РФ ст. 135.1 «Домогательство несовершеннолетнего с сексуальными целями», в которой установить ответственность за любое умышленное предложение о встрече, с которым лицо, достигшее 18-летнего возраста, при помощи Интернета или иных информационно-коммуникационных технологий обращается к несовершеннолетнему с целью совершения против него или нее полового преступления [19. С. 520-524]. Думается, что реализация этого предложения, сама по себе очень проблематичная, будет походить на стрельбу из пушек по воробьям. Гораздо более важно подумать над установлением уголовной ответственности за сексуальное домогательство при приеме на работу или на рабочем месте. В пользу такого соображения говорят следующее аргументы:

- сексуальное домогательство на рабочем месте посягает не только на половую свободу человека, но и на конституционное право на труд. Закономерно, что проблеме сексуального домогательства постоянно уделяется внимание со стороны Международной организации труда [20]. На значимость ответственности работодателей в рассматриваемом контексте указывают и российские исследователи трудовых отношений [21. С. 190-204];

- сексуальные домогательства в виде откровенных предложений вступить в половую связь (как условие приема на работу, ее сохранения или получения профессиональных преференций) со стороны работодателей и их представителей в настоящее время имеют довольно широкую распространенность (с чрезвычайно высокой латентностью). Существуют профессии с очень высоким риском оказаться жертвой подобных посягательств (в частности, прислуга в частных домовладениях). Однако такие случаи, как правило, не становятся предметом общественного внимания и правового реагирования, что делает практику сексуального домогательства привычной и безнаказанной. Это, в свою очередь, стимулирует ее даль- 
нейшее распространение. Прогнозы в этом отношении - неблагоприятные, учитывая состояние трудовой занятости молодежи в стране;

- развитие мировой цивилизации свидетельствует о появлении тренда правовой защиты жертв сексуального домогательства. Появляются специальные законы (как в Индии), на высоком уровне разрабатывается уголовная политика (как в США, где субъектом таких разработок выступает Государственный департамент) [22]. Российская Федерация в этом отношении явно отстает;

- во многих странах (кроме вышеназванных - в Республике Кении, КНР, Содружестве Багамских Островов) существует специальная уголовная ответственность за сексуальное домогательство [23]. Установление такой ответственности способствует достижению цели общей превенции.

Таким образом, целесообразно дополнение УК РФ ст. 133.1. «Сексуальное домогательство» в следующей редакции:

«Предложение об оказании сексуальных услуг при приеме на работу или на рабочем месте со стороны работодателя, его представителя или иного лица, обладающего властными полномочиями, -

наказывается штрафом в размере до ста тысяч рублей или в размере заработной платы или иного дохода осужденного за период до шести месяцев, либо обязательными работами на срок до трехсот шестидесяти часов, либо исправительными работами на срок до одного года, либо принудительными работами на срок до шести месяцев».

Большой остротой характеризуется проблема предупреждения сексуального домогательства. Международной организацией труда, юристами в ряде стран разработаны пособия, адресованные потенциальным и реальным его жертвам [24, 25], в которых разъяснены их законные права, сформулированы рекомендации, как вести себя в конфликтных ситуациях, к кому обратиться за помощью. Министерство по развитию положения женщин и детей Правительства Индии адресует соответствующие рекомендации работодателям, институтам и организациям [26]. Европарламент провозгласил нулевую толерантность по отношению к сексуальному домогательству в Европейском Союзе [27].

В России этому аспекту предупредительной деятельности не уделяется должного внимания, что следует признать существенным дефектом профессионального правового сознания. Важным шагом по исправлению сложившейся ситуации явится создание системы мониторинга сексуального домогательства на рабочем месте.

\section{Лuтература}

1. Конвенция Совета Европы по предотвращению и борьбе с насилием в отношении женщин и насилием в семье : закл. 11.05.2011 в Стамбуле // СПС «КонсультантПлюс».

2. Модельный закон о государственных гарантиях равных прав и равных возможностей для мужчин и женщин : (принят Постановлением № 26-11 на 26-м пленарном заседании Межпарламентской Ассамблеи государств-участников СНГ в Санкт-Петербурге 18.11.2005) // Информационный бюллетень Межпарламентской Ассамблеи государств участников Содружества Независимых Государств. 2006. № 37. С. 328-341. 
3. O защите женщин от насилия : рекомендация № R (2002) 5 Комитета министров Совета Европы // Совет Европы и Россия : сб. документов. М. : Юрид. лит., 2004. C. $780-829$.

4. Sexual Harassment in the Workplace 2018. URL: http://www.edisonresearch.com

5. О проекте Федерального закона № 467782-6 «О внесении изменений в Кодекс Российской Федерации об административных правонарушениях в части установления защиты прав женщин от сексуальных домогательств : Постановление Государственной Думы Федерального Собрания Российской Федерации шестого созыва от 17.09.2014 № 4891 // Собрание законодательства РФ. 2014. № 39. Ст. 5157.

6. Русские девушки и иностранцы на ЧМ по футболу. URL: http://www.super-mens.ru

7. Giddens A. The Transformation of Intimacy: Sexuality, Love and Eroticism in Modern Societies. Stanford : Stanford University Press, 1992. 216 p.

8. Платон. Диалоги : пер. с древнегреч. М. : Э, 2016. 766 с.

9. Ливий Тит. История Рима от основания города. М. : Э, 2017. 1344 с.

10. Авл Геллий. Аттические ночи. Кн. І-Х. СПб. : Гуманитарная акад., 2007. 480 с.

11. Фома Аквинский. Сумма теологии. М. : Либроком, 2012. T. IV. 688 с.

12. Алексеева А. Требуется секретарь без комплексов : истории жертв домогательств на работе // Сноб. 2017. 14 авг. URL: http://www.snob.ru

13. Ландо А. Откровения жертв сексуальных домогательств. URL: http://www.vse42.ru

14. The Sexual Harassment of Women at Workplace (Prevention, Prohibition and Redressal) : Act, 2013. URL: http://www.india.gov.in

15. Lok Sabha passes anti-rape bill // Hindustan Times. 2013. 19 March.

16. Уголовный кодекс Испании. М. : Зерцало, 1998. 218 с.

17. Penal Code of Algeria. URL: http://www. equalrightstrust.org

18. О судебной практике по делам о преступлениях против половой неприкосновенности и половой свободы личности : Постановление Пленума Верховного Суда РФ от 04.12.2014 № 16 // Рос. газ. 2014. 12 дек.

19. Букалерова Л.А., Атабекова А.А., Симонова М.А. О необходимости криминализации предложения несовершеннолетнему вступить в сексуальный контакт // Административное и муниципальное право. 2015. № 6. С. 520-524.

20. О занятости и достойном труде в целях обеспечения мира и потенциала противодействия : рекомендация № 205 Международной организации труда : принята на 106-й сессии Генеральной конференции МОТ в Женеве 16.06.2017 // СПС «КонсультантПлюс».

21. Шевченко О.А., Морощов П.Е., Чан Х.Х. Социальная ответственность работодателя в современных экономических условиях в России и во Вьетнаме: сравнительный анализ // Актуальные проблемы российского права. 2016. № 8. С. 190-204.

22. Sexual Harassment Policy. URL: http://www.state.gov

23. Overview and Workplace Sexual Harassment as a Crime. URL: http://www.endvownow.org

24. Guide on Prevention of Sexual Harassment in the Workplace International Labour Organization. 2010. 34 p.

25. Howard L.G. The Sexual Harassment Handbook. New Jersey : Book-mart Press, 2007. $223 \mathrm{p}$.

26. The Handbook on Sexual Harassment of Women at Workplace (Prevention, Prohibition and Redressal) : Act, 2013 : for Employers / Institutions / Organisations / Internal Complaints Committee / Local Complaints Committee. Government of India ; Ministry of Women and Child Devtlopment, 2015. 58 p.

27. European Parliament resolution of 26 October 2017 on combating sexual harassment and abuse in the EU (2017/2897(RSP). URL: http://www.europarl.europa.eu.

Kleymenov Ivan M., National Research University "Higher school of Economics» (SaintPetersburg, Russian Federation) 
SEXUAL HARASSMENT: CRIMINOLOGICAL AND CRIMINAL - LEGAL ASPECTS

Keywords: sexual harassment, workplace, abuse of power, criminalization.

\section{DOI: $10.17223 / 22253513 / 32 / 4$}

The relevance of scientific research of the problem of sexual harassment is determined by its active discussion in the materials of foreign and Russian press. The purpose of the present article is the assessment of the danger of sexual harassment in various areas: home and work. The subject of the analysis defined the choice of the following methods of research: formal and logical, comparative and legal, statistical, documentary and sociological.

The author conducted a survey of 342 residents of St. Petersburg, studied court practice about the responsibility for coercion to commit acts of sexual character. In the article on the basis of various empirical researches, including that of the author, the prevalence of sexual harassment lying outside the coercion to commit acts of sexual character, which can have a place both at home and at workplace, is shown. Domestic sexual harassment has a clear victimization aspect which is looked through in a thoughtless and provocative behavior of its victims.

A demonstration of such behavior during the FIFA World Cup-2018 shows that all legal prohibitions of domestic sexual harassment are senseless. At the same time, sexual harassment of the head or employer at a workplace is characterized by the increased public danger since it has a long psycho traumatic influence on the victim, often drives it into a corner, encroaches on the civil rights and freedoms, and undermines authority of the government power. Therefore such sexual harassment has to be forbidden in a penal order. In many countries (India, Spain, the Algerian Republic, the Republic of Kenya, etc.) there is special criminal liability for sexual harassment in a workplace. This reflects a worldwide tendency to strengthen counteraction to discrimination of the personality and protection of rights of the person and citizen.

The existing criminal legislation of Russia and practice of its application do not provide adequate criminal and legal counteraction to sexual harassment. The author proposes to add the Criminal Code of the Russian Federation with the article "Sexual harassment" establishing criminal liability for sexual harassment during a recruiting period or in a workplace that answers an urgent call of legal protection of the victims of sexual harassment. Sexual harassment in a workplace encroaches not only on sexual freedom of the person, but also on constitutional right to work. Its probability constantly increases taking into account the predicted tendencies of employment of youth.

\section{References}

1. European Council. (2011) Konventsiya Soveta Evropy po predotvrashcheniyu i bor'be s nasiliem $v$ otnoshenii zhenshchin i nasiliem $v$ sem'e: zakl. 11.05 .2011 v Stambule [Council of Europe Convention on Preventing and Combating Violence against Women and Domestic Violence: signed on May 11, 2011 in Istanbul]. [Online] Available from: http://www.consultant.ru/cons/cgi/online.cgi?req=doc;base=INT;n=59231\#01996303564504862.

2. Inter-Parliamentary Assembly of the States Parties to the Commonwealth of Independent States. (2006) Model Law on State Guarantees of Equal Rights and Equal Opportunities for Men and Women: (adopted by Resolution No. 26-11 at the 26th Plenary Meeting of the InterParliamentary Assembly of the CIS Member States in St. Petersburg, November 18, 2005). Informatsionnyy byulleten' Mezhparlamentskoy Assamblei gosudarstv - uchastnikov Sodruzhestva Nezavisimykh Gosudarstv. 37. pp. 328-341. (In Russian).

3. European Council. (2004) O zashchite zhenshchin ot nasiliya : rekomendatsiya № R (2002) 5 Komiteta ministrov Soveta Evropy [On protection of women from violence: recommendation No. R (2002) 5 of the Committee of Ministers of the Council of Europe]. In: Berstenev, Yu.Yu. (ed.) Sovet Evropy i Rossiya [Council of Europe and Russia]. Moscow: Yuridichesjaya literatura. pp. 780-829. 
4. Edison Research. (n.d.) Sexual Harassment in the Workplace 2018. [Online] Available from: http://www.edisonresearch.com.

5. Federal Assembly of the Russian Federation. (2014) Draft Federal Law No. 467782-6 "On Amendments to the Code of Administrative Offenses of the Russian Federation regarding the protection of the rights of women from sexual harassment: Resolution № 4891 of the sixth convocation of the Federal Assembly of the Russian Federation of September 17, 2014. Sobranie zakonodatel'stva RF - Legislative Bulletin of the Russian Federation. 39. Art. 5157. (In Russian).

6. Super-mens.ru. (n.d.) Russkie devushki i inostrantsy na ChM po futbolu [Russian girls and foreigners at the World Cup]. [Online] Available from: http://www.super-mens.ru.

7. Giddens, A. (1992) The Transformation of Intimacy: Sexuality, Love and Eroticism in Modern Societies. Stanford: Stanford University Press.

8. Plato. (2016) Dialogi [Dialogues]. Translated from Ancient Greek. Moscow: E.

9. Titus Livius. (2017) Istoriya Rima ot osnovaniya goroda [History of Rome from the founding of the city]. Moscow: E.

10. Aulus Gellius. (2007) Atticheskie nochi [Attic Nights]. Translated from Latin by A.B. Egorov, A.G. Grushevoy. St. Petersburg: Gumanitarnaya akad.

11. Thomas Aquinas. (2012) Summa teologii [The sum of theology]. Translated from Latin. Vol. 4. Moscow: Librokom.

12. Alekseeva, A. (2017) Trebuetsya sekretar' bez kompleksov: istorii zhertv domogatel'stv na rabote [A secretary without complexes needed: the history of victims of harassment at work]. Snob. 14th August. [Online] Available from: http://www.snob.ru.

13. Lando, A. (n.d.) Otkroveniya zhertv seksual'nykh domogatel'stv [Revelations of victims of sexual harassment]. [Online] Available from: http://www.vse42.ru

14. India. (2013) The Sexual Harassment of Women at Workplace (Prevention, Prohibition and Redressal): Act, 2013. [Online] Available from: http://www.india.gov.in.

15. Anon. (2013) Lok Sabha passes anti-rape bill. Hindustan Times. 19th March.

16. Kuznetsova, N.F. (ed.) (1998) Ugolovnyy kodeks Ispanii [Criminal Code of Spain]. Moscow: Zertsalo.

17. Algeria. (n.d.) Penal Code of Algeria. [Online] Available from: http://www.equal rightstrust.org.

18. The Supreme Court of the Russian Federation. (2014) O sudebnoy praktike po delam o prestupleniyakh protiv polovoy neprikosnovennosti i polovoy svobody lichnosti: Postanovlenie Plenuma Verkhovnogo Suda RF ot 04.12.2014 № 16 [On court practice in cases of crimes against sexual inviolability and sexual freedom of the individual: Resolution of the Plenum of the Supreme Court of the Russian Federation of December 4, 2014, No. 16]. Rossiyskaya gazeta. 12th December.

19. Bukalerova, L.A., Atabekova, A.A. \& Simonova, M.A. (2015) On the Necessity to Criminalize the Proposition to the Minor to Enter into Sexual Contact. Administrativnoe $i$ munitsipal'noe pravo - Administrative and Municipal Law. 6. pp. 520-524. (In Russian). DOI: 10.7256/1999-2807.2015.6.15570

20. ILO. (2017) On employment and decent work in order to ensure peace and potential for coping: Recommendation No. 205 of the International Labor Organization: adopted at the 106th session of the ILO General Conference in Geneva June 16, 2017. [Online] Available from: http://www.consultant.ru/cons/cgi/online.cgi?req=doc;base=INT;n=62322\#002427251413934 961. (In Russian).

21. Shevchenko, O.A., Moroshchov, P.E. \& Tran, Kh.Kh. (2016) Social responsibility of an employer in the current economic conditions in Russia and Vietnam: a comparative analysis. Aktual'nye problemy rossiyskogo prava - Actual Problems of the Russian Law. 8. pp. 190-204. (In Russian). DOI: 10.17803/1994-1471.2016.69.8.190-204

22. U.S. Department of State. (n.d.) Sexual Harassment Policy. [Online] Available from: http://www.state.gov.

23. Endvownow.org. (n.d.) Overview and Workplace Sexual Harassment as a Crime. [Online] Available from: http://www.endvownow.org. 
24. ILO. (2010) Guide on Prevention of Sexual Harassment in the Workplace. [s.l., s.n.].

25. Howard, L.G. (2007) The Sexual Harassment Handbook. New Jersey: Book-mart Press.

26. India. (2015) The Handbook on Sexual Harassment of Women at Workplace (Prevention, Prohibition and Redressal): Act, 2013: for Employers / Institutions / Organisations / Internal Complaints Committee / Local Complaints Committee. Government of India; Ministry of Women and Child Devtlopment.

27. EU. (2017) European Parliament resolution of 26 October 2017 on combating sexual harassment and abuse in the EU (2017/2897(RSP). [Online] Available from: http://www.europarl.europa.eu. 